\title{
An Application of Similarity Measure of Intuitionistic Fuzzy Soft Set based on distance in Medical Diagnosis
}

\author{
Dr. N. Sarala ${ }^{1}$, B. Suganya ${ }^{2}$ \\ ${ }^{1}$ Department of Mathematics, A.D.M College for Women, Nagapattinam (India) \\ ${ }^{2}$ Department of Mathematics, Bharathidasan University Constituent College of Arts and Science, Nagapattinam.(India)
}

\begin{abstract}
In this article, the concept of similarity measure for intuitionistic fuzzy soft sets based on distance between two intuitionistic fuzzy soft sets, some examples and basic properties are also studied. An algorithm is developed in intuitionistic fuzzy soft set and an example is given to illustrate possible application in a medical diagnosis problem
\end{abstract}

Keywords: Soft set, fuzzy soft set, intuitionistic fuzzy soft set, normalized Hamming Distance, normalized Euclidean Distance, Similarity Measure

\section{Introduction}

The concept of fuzzy set theory was introduced by Prof. L. A. Zadeh [23] in 1965. Several researchers have extended the concept of fuzzy set in multi directions. The traditional fuzzy set is characterized by the membership value or the grade of membership value. In some real life problems in expert system, belief system, information fusion and so on, we must consider the truth-membership as well as the falsity-membership for proper description of an object in uncertain, ambiguous environment. Intuitionistic fuzzy set [12] is appropriate for such a situation. The intuitionistic fuzzy sets can only handle the incomplete information considering both the truth-membership (and simply membership) and falsity-membership (or non-membership) values. Soft set theory [15] has enriched its potentiality since its introduction by Molodtsov in 1999.

Similarity measure is an important topic in the fuzzy set theory. Similarity measure indicates degree of similarity between two fuzzy sets. Wang [22] first introduced the concept of similarity measure of fuzzy sets and gave a computational formula. Science then, similarity measure of fuzzy sets has attracted several researchers' interest and has been investigated more. Similarity measure of fuzzy sets is now being extensively applied in many research fields.

Similarity measure between two fuzzy sets (intuitionistic fuzzy sets, intuitionistic fuzzy soft sets) have been defined by many authors[18,20,21].There are different techniques for measuring similarity measure between two fuzzy sets or between two fuzzy soft sets. Some of them are based on distances and some others are based on matching function. There are techniques based on set-theoretic approach also. Some properties are common to these measures and some are not, which influence the choice of the measure to be used in several applications.

P. Majumdar and S. K. Samanta [8,9] have studied the similarity measure of soft sets, fuzzy soft sets and intuitionistic fuzzy soft sets. Cagman [5] studied similarity measure of intuitionistic fuzzy soft sets. A. Mukherjee and S. Sarkar [16] introduced several similarity measures for interval valued intutionistic fuzzy soft sets

In this paper first we present preliminaries, distances between two intuitionistic fuzzy soft sets are defined and similarity measure between two intuitionistic fuzzy soft sets are proposed. An application of similarity measure between intuitionistic fuzzy soft sets in a medical diagnosis problem is also illustrated.

\section{Preliminaries}

In this section, we have presented the basic definition related to fuzzy sets, soft sets, fuzzy soft sets and we presented the basic concepts of intuitionistic fuzzy soft set theory which would be used in the sequel.

\section{Definition 2.1 [11]}

Let $\mathrm{E}$ be a crisp set. Then a fuzzy set $\mu$ over $\mathrm{E}$ is a function from $\mathrm{E}$ into $[0,1]$.

\section{Definition2.2 : Soft set [11]}

Suppose that $U$ is an initial universe set and $E$ is a set of parameters, let $\mathrm{P}(\mathrm{U})$ denotes the power set of $\mathrm{U}$.A pair $(\mathrm{F}, \mathrm{E})$ is called a soft set over $U$ where $F$ is a mapping given by $F$ : $\mathrm{E} \rightarrow \mathrm{P}(\mathrm{U})$.

Clearly, a soft set is a mapping from parameters to $\mathrm{P}(\mathrm{U})$, and it is not a set, but a parameterized family of subsets of the Universe.

\section{Definition 2.3. Fuzzy soft set [10]}

Let $U$ be an initial Universe set and $E$ be the set of parameters. Let $A \subset E$. A pair (F, A) is called fuzzy soft set over $U$ where $F$ is a mapping given by $F: A \rightarrow I^{U}$, Where $I^{U}$ denotes the collection of all fuzzy subsets of $U$.

Definition 2.4. Fuzzy soft class [10]

Let $U$ be an initial Universe set and $E$ be the set of attributes. Then the pair $(\mathrm{U}, \mathrm{E})$ denotes the collection of all fuzzy soft 


\section{International Journal of Science and Research (IJSR) \\ ISSN (Online): 2319-7064 \\ Index Copernicus Value (2013): 6.14 | Impact Factor (2014): 5.611}

sets on $U$ with attributes from $E$ and is called a fuzzy soft class.

Let $U$ be an initial universe, and $E$ be the set of all possible parameters under consideration with respect to $U$. The set of all subsets of $U$, i.e. the power set of $U$ is denoted by $P(U)$ and the set of all Intuitionistic fuzzy subsets of $U$ is denoted by $I F^{U}$. Let $A$ be a subset of $E$.

\section{Definition 2.5[10]}

An intuitionistic fuzzy set $A$ over the universe $U$ can be defined as follows

$A=\left\{\left(x, \mu_{A}(x), v_{A}(x): x \in U\right\}\right.$, where $\mu_{A}(x): U \rightarrow[0,1], v_{A}(x): U$ $\rightarrow[0,1]$ with the property $0 \leq \mu_{A}(x)+v_{A}(x) \leq 1 \forall x \in U$. The values $\mu_{A}(x)$ and $v_{A}(x)$ represent the degree of membership and non-membership of $x$ to $A$ respectively. $\pi_{A}(x)=1-\left(\mu_{A}\right.$ $\left.(x)+v_{A}(x)\right)$ is called the intuitionistic fuzzy index.

\section{Definition: 2.6 [10]}

An intuitionistic fuzzy set $A$ over the universe $U$ defined as $A=\{(x, 0,1): x \in U\}$ is said to be intuitionistic fuzzy null set and is denoted by 0 .

\section{Definition :2.7[10]}

An intuitionistic fuzzy set $A$ over the universe $U$ defined as $A=\{(x, 1,0): x \in U\}$ is said to be intuitionistic fuzzy absolute set and is denoted by 1 .

\section{Definition :2.8 [11]}

Let $A=\left\{\left(x, \mu_{A}(x), v_{A}(x): x \in U\right\}\right.$ be an intuitionistic fuzzy set over the universe $U$, where $\mu_{A}(x): U \rightarrow[0,1], v_{A}(x): U \rightarrow[0,1]$ with the property $0 \leq \mu_{A}(x)+v_{A}(x) \leq 1 \forall x \in U$. Complement of $\boldsymbol{A}$ is denoted by $A^{c}$ and defined as the intuitionistic fuzzy set $A^{c}=\left\{\left(x, v_{A}(x), \mu_{A}(x): x \in U\right\}\right.$.

\section{Definition :2.9 [10]}

Let $U$ be an initial universe set and $E$ be the set of parameters. Let $I F^{U}$ denote the collection of all intuitionistic fuzzy subsets of $U$. Let $A \subseteq E$. A pair $(F, A)$ is called an intuitionistic fuzzy soft set over $U$ where $F$ is a mapping given by $F: A \rightarrow I F^{U}$.

\section{Definition :2.10: Intuitionistic Fuzzy Soft Set (IFSS)}

Let $U$ be an initial universe, $E$ be the set of parameters and A $\subseteq$ E. A pair $(F, E)$ is called an intuitionistic fuzzy soft set (IFSS) over $\mathrm{U}$, where $F A$ is a mapping given by $F A: \mathrm{E} \rightarrow \mathrm{I}^{\mathrm{U}}$ , where $\mathrm{I}^{\mathrm{U}}$ denotes the collection of all intuitionistic fuzzy subsets of $\mathrm{U}$.

\section{Example :2.11}

Suppose that $U=\left\{\mathrm{u}_{1}, \mathrm{u}_{2}, \mathrm{u}_{3}, \mathrm{u}_{4}\right\}$ be a set of four sarees and $\mathrm{E}$ $=\left\{\right.$ yellow $\left(\mathrm{e}_{1}\right)$,blue $\left(\mathrm{e}_{2}\right)$, green $\left.\left(\mathrm{e}_{3}\right)\right\}$ be a set of parameters. If $\mathrm{A}=\left\{\mathrm{e}_{1}, \mathrm{e}_{2}\right\} \in \mathrm{E}$.

Let $\mathrm{F}\left(\mathrm{e}_{1}\right)=\left\{\left(\mathrm{u}_{1}, 0.3,0.7\right),\left(\mathrm{u}_{2}, 0.8,0.1\right),\left(\mathrm{u}_{3}, 0.4,0.2\right),\left(\mathrm{u}_{4}, 0.6,0.2\right)\right\}$ $F\left(\mathrm{e}_{2}\right)=\left\{\left(\mathrm{u}_{1}, 0.8,0.1\right),\left(\mathrm{u}_{2}, 0.9,0.1\right),\left(\mathrm{u}_{3}, 0.4,0.5\right),\left(\mathrm{u}_{4}, 0.2,0.3\right)\right\}$ then we write intuitionistic fuzzy soft set is $(F, \mathrm{E})=\left\{\left(\mathrm{e}_{1}\right)\right.$

$F\left(\mathrm{e}_{1}\right)=\left\{\left(\mathrm{u}_{1}, 0.3,0.7\right),\left(\mathrm{u}_{2}, 0.8,0.1\right),\left(\mathrm{u}_{3}, 0.4,0.2\right),\left(\mathrm{u}_{4}, 0.6,0.2\right)\right\}$

$\left.F\left(\mathrm{e}_{2}\right)=\left\{\left(\mathrm{u}_{1}, 0.8,0.1\right),\left(\mathrm{u}_{2}, 0.9,0.1\right),\left(\mathrm{u}_{3}, 0.4,0.5\right),\left(\mathrm{u}_{4}, 0.2,0.3\right)\right\}\right\}$

\section{Definition :2.12 [10]}

Union of two intuitionistic fuzzy soft sets $(F, A)$ and $(G, B)$ over $(U, E)$ is an Intuitionistic fuzzy soft set $(H, C)$ where $C$ $=A \cup B$ and $\forall \varepsilon \in \mathrm{C}$,

$$
\mathrm{H}(\varepsilon)= \begin{cases}\mathrm{F}(\varepsilon), & \text { if } \varepsilon \in \mathrm{A}-\mathrm{B} \\ \mathrm{G}(\varepsilon), & \text { if } \varepsilon \in \mathrm{B}-\mathrm{A} \\ \mathrm{F}(\varepsilon) \cup \mathrm{G}(\varepsilon), & \text { if } \varepsilon \in \mathrm{A} \cap \mathrm{B}\end{cases}
$$

and is written as $(\mathrm{F}, \mathrm{A}) \sim(\mathrm{G}, \mathrm{B})=(\mathrm{H}, \mathrm{C})$

\section{Definition :2.13 [11]}

Let $(F, A)$ and $(G, B)$ be two intuitionistic fuzzy soft sets over $(U, E)$. Then intersection $(F, A)$ and $(G, B)$ is an intuitionistic fuzzy soft set $(H, C)$ where $C=A \cap B$ and $\forall \varepsilon$ $\in \mathrm{C}, \mathrm{H}(\varepsilon)=\mathrm{F}(\varepsilon) \tilde{\cap} \mathrm{G}(\varepsilon)$.

We write $(\mathrm{F}, \mathrm{A}) \tilde{\cap}(\mathrm{G}, \mathrm{B})=(\mathrm{H}, \mathrm{C})$.

\section{Definition :2.14 [5]}

For two Intuitionistic fuzzy soft sets $(F, A)$ and $(G, B)$ over $(U, E)$, we say that $(F, A)$ is an intuitionistic fuzzy soft subset of $(G, B)$, if

(i) $A \subseteq B$,

(ii) For all $\varepsilon \in A, F(\varepsilon) \subseteq \mathrm{G}(\varepsilon)$.

and is written as $(F, A) \subseteq(G, B)$.

\section{Distance and Similarity Measure of Intuitionistic fuzzy soft set}

In this section, we first present the basic definitions of distances between two intuitionistic fuzzy soft sets [13] are useful for subsequent discussions. Then, we define some distances and similarity measures of IFS-sets.

Let $(F, A)=\left\{F\left(e_{i}\right), \quad i=1,2,3, \ldots . . n\right\}$ and $(G, B)=\left\{G\left(e_{i}\right)\right.$, $\mathrm{i}=1,2,3, \ldots \ldots \mathrm{n}\}$ be two intuitionistic fuzzy soft sets where $F\left(e_{i}\right)$ is the $e_{i}$ approximations of $(F, E)$ and $G\left(e_{i}\right)$ is the $e_{i}$ approximations of $(\mathrm{G}, \mathrm{E})$.

Now we define various distance measures $d$ are present in literature. .

\section{Definition 3 .1[5]}

Let $(F, E)$ and $(G, E)$ be two intuitionistic fuzzy soft sets over $(\mathrm{U}, \mathrm{E})$. Then distance measure between $(\mathrm{F}, \mathrm{E})$ and $(\mathrm{G}, \mathrm{E})$ is defined as

1. The Hamming distance

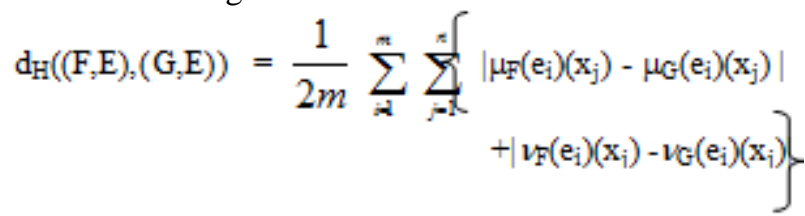

2. The normalized Hamming distance

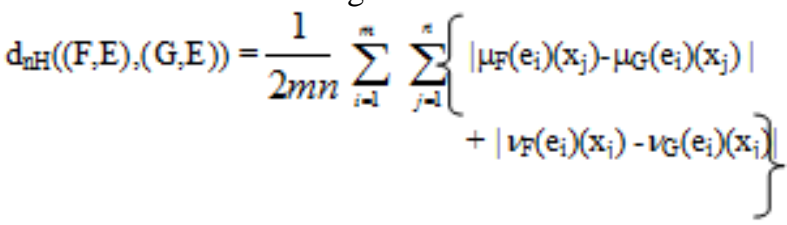




\section{International Journal of Science and Research (IJSR) \\ ISSN (Online): 2319-7064 \\ Index Copernicus Value (2013): 6.14 | Impact Factor (2014): 5.611}

3. The Euclidean distance

$$
\begin{gathered}
\mathrm{d}_{\mathrm{E}}((\mathrm{F}, \mathrm{E}),(\mathrm{G}, \mathrm{E}))\left\{\frac{1}{2 m} \sum_{i=1}^{m} \sum_{j=1}^{n}\left|\mu_{F}\left(\mathrm{e}_{i}\right)\left(\mathrm{x}_{\mathrm{j}}\right)-\mu_{\mathrm{G}}\left(\mathrm{e}_{\mathrm{i}}\right)\left(\mathrm{x}_{\mathrm{j}}\right)\right|^{2}+\right. \\
\left.\mid \nu_{\mathrm{F}}\left(\mathrm{e}_{\mathrm{i}}\right)\left(\mathrm{x}_{\mathrm{i}}\right)-v_{\mathrm{G}}\left(\mathrm{e}_{\mathrm{i}}\right)\left(\mathrm{x}_{\mathrm{i}}\right)\right\}^{1 / 2}
\end{gathered}
$$

4. The normalized Euclidean distance

$$
\begin{gathered}
d n_{\mathbb{E}}((\mathrm{F}, \mathrm{E}),(\mathrm{G}, \mathrm{E}))\left\{\frac{1}{2 m n} \sum_{i=1}^{n} \sum_{j=i}^{n}\left|\mu_{F}\left(\mathrm{e}_{\mathrm{i}}\right)\left(\mathrm{x}_{\mathrm{j}}\right)-\mu_{\mathrm{G}}\left(\mathrm{e}_{\mathrm{i}}\right)\left(\mathrm{x}_{\mathrm{j}}\right)\right|^{2}+\right. \\
\left|v_{\mathrm{F}}\left(\mathrm{e}_{\mathrm{i}}\right)\left(\mathrm{x}_{\mathrm{i}}\right)-v_{\mathrm{G}}\left(\mathrm{e}_{\mathrm{i}}\right)\left(\mathrm{x}_{\mathrm{i}}\right)\right|^{2}
\end{gathered}
$$

\section{Example : 3.2}

Let $\mathrm{U}=\left\{x_{1}, x_{2}\right\}$ be the universal set and $\mathrm{E}=\left\{\mathrm{e}_{1}, \mathrm{e}_{2}\right\}$ be the set of parameters . Let $(\mathrm{F}, \mathrm{E})$ and $(\mathrm{G}, \mathrm{E})$ be two intuitionistic fuzzy soft sets over $U$ such that $(F, E)$ and $(\mathrm{G}, \mathrm{E})$ is given by

\begin{tabular}{|c|c|c|}
\hline$(\mathbf{F}, \mathbf{E})$ & $\mathbf{e}_{\mathbf{1}}$ & $\mathbf{e}_{\mathbf{2}}$ \\
\hline $\boldsymbol{x}_{\mathbf{1}}$ & $(0.3,0.6)$ & $(0.7,0.2)$ \\
\hline $\boldsymbol{x}_{\mathbf{2}}$ & $(0.6,0.1)$ & $(0.6,0.2)$ \\
\hline \multicolumn{3}{|c|}{ and } \\
\hline
\end{tabular}

\begin{tabular}{|c|c|c|}
\hline$(\mathbf{G}, \mathbf{E})$ & $\mathbf{e}_{\mathbf{1}}$ & $\mathbf{e}_{\mathbf{2}}$ \\
\hline $\boldsymbol{x}_{\mathbf{1}}$ & $(0.1,0.8)$ & $(0.2,0.7)$ \\
\hline $\boldsymbol{x}_{\mathbf{2}}$ & $(0.6,0.4)$ & $(0.4,0.5)$ \\
\hline
\end{tabular}

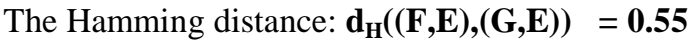

\section{Theorem:3.3}

Let $(F, E)$ and $(G, E)$ be two intuitionistic fuzzy soft sets over $(\mathrm{U}, \mathrm{E})$. Then distance measure between $(\mathrm{F}, \mathrm{E})$ and $(\mathrm{G}, \mathrm{E})$ is defined as $d((F, E),(G, E))$, which satisfies the following properties.

(D1) $0 \leq \mathrm{d}((\mathrm{F}, \mathrm{E}),(\mathrm{G}, \mathrm{E})) \leq 1$;

(D2) d ((F,E), (G,E)) =0, if $(\mathrm{F}, \mathrm{E})=(\mathrm{G}, \mathrm{E})$;

(D3) $d((F, E),(G, E))=d((G, E),(F, E))$;

(D4) Let $(\mathrm{H}, \mathrm{C})$ be a intuitionistic fuzzy soft set, if $(\mathrm{F}, \mathrm{E}) \subseteq$ $(\mathrm{G}, \mathrm{E}) \subseteq(\mathrm{H}, \mathrm{E})$.

Then $\mathrm{d}((\mathrm{F}, \mathrm{E}),(\mathrm{G}, \mathrm{E})) \leq \mathrm{d}((\mathrm{F}, \mathrm{E}),(\mathrm{H}, \mathrm{E}))$ and $\mathrm{d}((\mathrm{G}, \mathrm{E}),(\mathrm{H}, \mathrm{E})) \leq$ d ((F,E), (H,E))

\section{Definition: 3.4}

Let $\mathrm{U}$ be universe and $\mathrm{E}$ be the set of parameters Suppose $(F, E)$ and $(G, E)$ be two intuitionistic fuzzy soft sets over $U$, the similarity measure based on the normalized Hamming distance between them is defined as

$$
\begin{aligned}
\mathrm{S}_{\mathrm{nH}}((\mathrm{F}, \mathrm{E}),(\mathrm{G}, \mathrm{E}))=1-\frac{1}{2 m n} \sum_{\mathrm{i}=1}^{m} \sum_{\mathrm{j}=1}^{n}\left|\mu_{\mathrm{F}}\left(\mathrm{e}_{\mathrm{i}}\right)\left(\mathrm{x}_{\mathrm{j}}\right)-\mu_{\mathrm{G}}\left(\mathrm{e}_{\mathrm{i}}\right)\left(\mathrm{x}_{\mathrm{j}}\right)\right| \\
+\left|v_{\mathrm{F}}\left(\mathrm{e}_{\mathrm{i}}\right)\left(\mathrm{x}_{\mathrm{j}}\right)-v_{\mathrm{G}}\left(\mathrm{e}_{\mathrm{i}}\right)\left(\mathrm{x}_{\mathrm{j}}\right)\right|
\end{aligned}
$$

\section{Example :3.5}

Let us consider the example 3.2, then the similarity measure of Hamming distance of $(\mathrm{F}, \mathrm{E})$ and $(\mathrm{G}, \mathrm{E})$ is given by $\mathrm{S}_{\mathrm{H}}((\mathrm{F}, \mathrm{E}),(\mathrm{G}, \mathrm{E}))=1-0.55=0.45$

\section{Theorem 3.6}

Let $(F, E)$ and $(G, E)$ be two intuitionistic fuzzy soft sets over $(\mathrm{U}, \mathrm{E})$. Then similarity measure between $(\mathrm{F}, \mathrm{E})$ and $(\mathrm{G}, \mathrm{E})$ is defined as $s((F, E),(G, B))$, which satisfies the following properties.

(S1) $0 \leq \mathrm{s}((\mathrm{F}, \mathrm{E}),(\mathrm{G}, \mathrm{E})) \leq 1$;

(S2) $s((\mathrm{~F}, \mathrm{E}),(\mathrm{G}, \mathrm{E}))=1$, if $(\mathrm{F}, \mathrm{E})=(\mathrm{G}, \mathrm{E})$;

(S3) $s((\mathrm{~F}, \mathrm{~A}),(\mathrm{G}, \mathrm{B}))=\mathrm{s}((\mathrm{G}, \mathrm{E}),(\mathrm{F}, \mathrm{E}))$;

(S4) Let $(\mathrm{H}, \mathrm{E})$ be a intuitionistic fuzzy soft set,

if $(\mathrm{F}, \mathrm{E}) \subseteq(\mathrm{G}, \mathrm{E}) \subseteq(\mathrm{H}, \mathrm{E})$,

then $s((F, E),(H, E)) \leq s((F, E),(G, E))$ and $s((F, E),(H, E)) \leq$ $s((G, B),(H, E))$.

Throughout this, we assume that the intuitionistic fuzzy soft sets $(F, E)$ and $(G, E)$ have the same parameters.

\section{Theorem 37}

If $S(F, G)$ be the similarity measure between two IFSSs $(F, E)$ and $(G, E)$ then

(i) $\mathrm{S}(\mathrm{F}, \mathrm{G})=\mathrm{S}(\mathrm{G}, \mathrm{F})$

(ii) $0 \leq \mathrm{S}(F, G) \leq 1$

(iii) $\mathrm{S}(\mathrm{F}, \mathrm{G})=1$ if and only if $(\mathrm{F}, \mathrm{E})=(\mathrm{G}, \mathrm{E})$.

Proof:

Proof easily can be made by using Definition 3.4

\section{Application of Medical Diagnosis Problem}

In this section we construct a method for a medical diagnosis problem based on similarity measure of intuitionistic fuzzy soft sets (IFSSs). The algorithm of this method is as follows:

\section{Algorithm}

Step 1: Construct a IFSS (F,E) over the universe U based on an medical knowledge.

Step 2: Construct a IFSS (G,E) over the universe U based on a responsible person for the illness.

Step 3: Calculate the distances of $(F, E)$ and $(G, E)$.

Step 4: Calculate similarity measure of (F,E) and (G,E).

Step 5: Estimate result by using the similarity.

Here we are giving an example of medical diagnosis problem. The similarity measure of two IFSSs based on normalized Hamming distance can be applied. Then we find the similarity measure of these IFSSs.

\section{Example 4.1}

Suppose that there are two patients $\mathrm{G}$ and $\mathrm{H}$ in a hospital with symptoms fever, rash, red eyes, joint pain. Let $U$ be the universal set be the universal set, which contains only three elements $\quad x_{1}$ (heavy), $\quad x_{2}$ (medium) and $x_{3}$ (normal) i.e. $\mathrm{U}=\left\{x_{1}, x_{2}, x_{3}\right\}$.

Here the set of parameters $\mathrm{E}$ is the set of certain approximations determined by the Hospital.

Let $\mathrm{E}=\left\{\mathrm{e}_{1}, \mathrm{e}_{2}, \mathrm{e}_{3}, \mathrm{e}_{4}\right\}$, where $\mathrm{e}_{1}=$ fever, $\mathrm{e}_{2}=$ rash, $\mathrm{e}_{3}=$ red eyes, $\mathrm{e}_{4}=$ joint pain.

Step 1: Construct a IFSS (F,E) for chickenpox over U as given in Table1.1, which can be prepared with the help of medical knowledge. 


\section{International Journal of Science and Research (IJSR) ISSN (Online): 2319-7064 \\ Index Copernicus Value (2013): 6.14 | Impact Factor (2014): 5.611}

Table 1.1: intuitionistic Fuzzy soft set (F, E) for

chickenpox. Each symptom is described by two numbers i.e. membership $\mu$, non-membership $v$.

\begin{tabular}{|c|c|c|c|c|}
\hline (F,E) & $\mathbf{e}_{1}$ & $\mathbf{e}_{2}$ & $\mathbf{e}_{3}$ & $\mathbf{e}_{4}$ \\
\hline $\boldsymbol{x}_{\mathbf{1}}$ & $(0.6,0.2)$ & $(0.6,0.1)$ & $(0.4,0.2)$ & $(0.4,0.4)$ \\
\hline $\boldsymbol{x}_{2}$ & $(0.4,0.2)$ & $(0.5,0.4)$ & $(0.6,0.1)$ & $(0.7,0.1)$ \\
\hline $\boldsymbol{x}_{3}$ & $(0.4,0.5)$ & $(0.6,0.1)$ & $(0.8,0.0)$ & $(0.6,0.3)$ \\
\hline
\end{tabular}

Step 2: Similarly, we construct a IFSS for the two patients under consideration as given in Table 1.2, and 1.3

Table 1.2: intuitionistic Fuzzy soft set $(G, E)$ for the first patient

\begin{tabular}{|c|c|c|c|c|}
\hline$(\mathbf{G , E )}$ & $\mathbf{e}_{1}$ & $\mathbf{e}_{2}$ & $\mathbf{e}_{3}$ & $\mathbf{e}_{\mathbf{4}}$ \\
\hline $\boldsymbol{x}_{\mathbf{1}}$ & $(0.3,0.6)$ & $(0.7,0.2)$ & $(0.6,0.3)$ & $(0.5,0.3)$ \\
\hline $\boldsymbol{x}_{2}$ & $(0.6,0.1)$ & $(0.6,0.2)$ & $(0.7,0.0)$ & $(0.1,0.4)$ \\
\hline $\boldsymbol{x}_{3}$ & $(0.3,0.6)$ & $(0.1,0.7)$ & $(0.1,0.7)$ & $(0.2,0.5)$ \\
\hline
\end{tabular}

Table 1.3: intuitionistic Fuzzy soft set (H, E) for the second

\begin{tabular}{|c|c|c|c|c|}
\hline$(\mathbf{H}, \mathbf{E})$ & $\mathbf{e}_{1}$ & $\mathbf{e}_{\mathbf{2}}$ & $\mathbf{e}_{3}$ & $\mathbf{e}_{\mathbf{4}}$ \\
\hline $\boldsymbol{x}_{\mathbf{1}}$ & $(0.1,0.8)$ & $(0.2,0.7)$ & $(0.3,0.6)$ & $(0.5,0.4)$ \\
\hline $\boldsymbol{x}_{\mathbf{2}}$ & $(0.6,0.4)$ & $(0.4,0.5)$ & $(0.3,0.6)$ & $(0.3,0.6)$ \\
\hline $\boldsymbol{x}_{\mathbf{3}}$ & $(0.6,0.3)$ & $(0.3,0.6)$ & $(0.2,0.7)$ & $(0.2,0.6)$ \\
\hline
\end{tabular}

Step 3: Calculate Hamming distance of $(F, E)$, (G,E) and $(\mathrm{H}, \mathrm{E})$

Now by definition,

the normalized Hamming distance between $(F, E)$ and $(G, E)$ is given by $\mathbf{d}_{\mathbf{n}}((\mathbf{F}, \mathbf{E}),(\mathbf{G}, \mathbf{E}))=\mathbf{0 . 2 6}$

the normalized Hamming distance between $(\mathrm{F}, \mathrm{E})$ and $(\mathrm{H}, \mathrm{E})$ is given by $\mathbf{d}_{\mathbf{n}}((\mathbf{F}, \mathbf{E}),(\mathbf{H}, \mathbf{E}))=\mathbf{0 . 3 4}$

Step 4: Calculate similarity measure between $(F, E)$, $(\mathrm{G}, \mathrm{E})$ and $(\mathrm{H}, \mathrm{E})$ :

Now by definition,

Similarity measure between $(\mathrm{F}, \mathrm{E})$ and $(\mathrm{G}, \mathrm{E})$ is given by

$\mathrm{S}_{\mathrm{nH}}((\mathrm{F}, \mathrm{E}),(\mathrm{G}, \mathrm{E}))=\mathbf{0 . 7 4}$

Similarity measure between $(\mathrm{F}, \mathrm{E})$ and $(\mathrm{H}, \mathrm{E})$ is given by

$\mathrm{S}_{\mathrm{nH}}((\mathrm{F}, \mathrm{E}),(\mathrm{H}, \mathrm{E}))=0.65$

Step 5: Therefore we conclude that the first person is possibly suffering from chickenpox.

\section{Conclusion}

In this paper we have defined distances between IFSSs and proposed similarity measures of IFSSs based on distances between IFSSs. Then we construct a medical diagnosis based on similarity measures. In view of our discussion, we can conclude that, first patient is suffering from chickenpox .It is hoped that our work would help enhancing this study on IFSSs

\section{References}

[1] B.Ahmad and Athar Kharal, "On Fuzzy Soft Sets", Advances in Fuzzy Systems,2009.

[2] N.Cagman, S.Enginoglu and F.Citak, Fuzzy soft set theory and its application, Iran. J. Fuzzy Syst., 8 (2011) 137-147
[3] Dusmanta Kumar Sut, "An Application of Similarity of Fuzzy Soft sets in Decision Making" Int.J.Computer Technology \& Applications, Vol 3(2), 742-745

[4] A. Kharal, "Distance and Similarity measures for soft sets", New Math. Nat. Comput., 6 (2010) ,321-334.

[5] Naim Cagman, Irfan Deli, Similarity measure of intuitionistic fuzzy soft sets and their decision making, arXiv : 1301.0456vI [ math.LO] 16 dec 2013.

[6] N. Cagman and S . Karata s, Intuitionistic fuzzy soft set theory and its decision making, Journal of Intelligent and Fuzzy Systems, DOI: 10.3233IFS-2012-06015-17.

[7] Y. Jiang, Y. Tang, Q. Chen, H. Liu and J. Tung, Interval -valued intuitionistic fuzzy soft sets and their properties, Computers and Mathematics with Applications 60(2010) 906- 918

[8] P.Majumdar and S. K. Samanta, On similarity measures of fuzzy soft sets,International Journal of Advance Soft Computing and Applications 3 ( 2) July 2011.

[9] P.Majumder and S. K. Samanta, On distance based similarity measure between intuitionistic fuzzy soft sets, Anusandhan 12 (22) (2010) 41-50.

[10] P. K. Maji, R. Biswas and A. R. Roy, Soft set theory, Computers and Mathematics with Applications 45 (4-5) (2003) 555-562.

[11]P. K. Maji, R. Biswas and A. R. Roy, Fuzzy Soft Sets, Journal of Fuzzy Mathematics 9 (3) (2001) 589-602.

[12] P.K. Maji,A.R. Roy, R. Biswas, On Intuitionistic Fuzzy Soft Sets. The Journal of Fuzzy Mathematics, 12(3) (2004) 669-683.

[13] P.K. Maji, R.Biswas A.R. Roy, Intuitionistic Fuzzy Soft Sets. The Journal of Fuzzy Mathematics, 9(3) (2001) 677-692.

[14] P.K. Maji, R. Bismas and A.R. Roy, Soft set theory, Computers and Mathematics with Applications, 45 (2003) 555-562.

[15]D. Molodtsov, Soft set theory-first results, Computers and Mathematics with Application 37 (1999) 19-31.

[16]A. Mukherjee and S. Sarkar, Similarity measures for interval-valued intuitionistic fuzzy soft sets and its application in medical diagnosis problem, New Trends In Mathematical Sciences 2(3) (2014) 159-165.

[17] Sarala and Suganya, "Some Properties of Fuzzy Soft Groups" . IOSR Journal of Mathematics(IOSR-JM) Volume 10, Issue 2 Ver. III (Mar-Apr.2014), P 36-40,

[18] Sarala and Suganya," On Normal Fuzzy Soft Groups". International Journal of Mathematics Trend and Technology - Volume 10 Number 2 - Jun 2014,

[19] Sarala and Suganya," Q- Fuzzy Soft Ring”, International Journal of Engineering Research \& Technology (IJERT), Vol. 4 Issue 02, February-2015

[20] Sarala and Suganya, "The Maximum and Minimum Conditions in Fuzzy Soft Ideals of a Fuzzy Soft Lattice", International Journal of Science and Research (IJSR), Volume 4 Issue 4, April 2015, pp:1467-1470

[21]E. Szmidt and J.Kacprzyk , Distances between intuitionistic fuzzy sets, Fuzzy Sets and Systems 114 (2000) 505-518.

[22] Weiqiong Wang, Xiaolong Xin, Distance measure between intuitionistic fuzzy sets, PatternRecognition Letters 26 (2005) 2063-2069.

[23] L.A. Zadeh, Fuzzy Sets, Inform. and Control, 8 (1965) 338-353 


\section{International Journal of Science and Research (IJSR) \\ ISSN (Online): 2319-7064}

Index Copernicus Value (2013): 6.14 | Impact Factor (2014): 5.611

[24]Zeshu Xu, Some similarity measures of intuitionistic fuzzy sets and their applications to multiple attribute decision making, Fuzzy Optim. Decis. Mak. 6 (2007) 109-121.

[25]Zhizhen Liang and Pengfei Shi, Similarity measures on intuitionistic fuzzy sets, Pattern Recognition Letters 24 (2003) 2687-2693. 